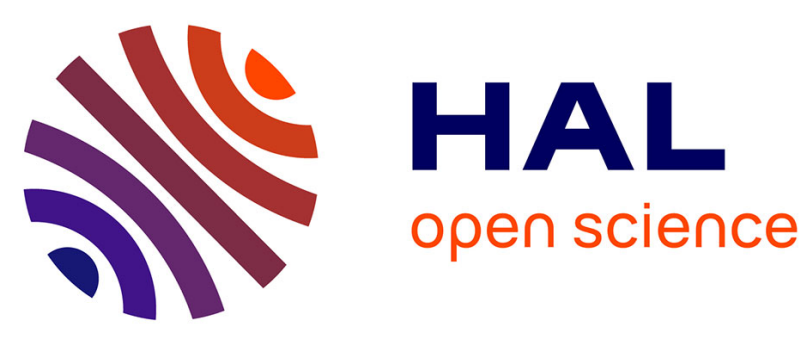

\title{
Centronuclear Myopathies
}

\author{
Norma B. Romero, Marc Bitoun
}

\section{To cite this version:}

Norma B. Romero, Marc Bitoun. Centronuclear Myopathies. Seminars in Pediatric Neurology, 2011, 18 (4), pp.250-256. 10.1016/j.spen.2011.10.006 . hal-02451115

\section{HAL Id: hal-02451115 https://hal.science/hal-02451115}

Submitted on 23 Jan 2020

HAL is a multi-disciplinary open access archive for the deposit and dissemination of scientific research documents, whether they are published or not. The documents may come from teaching and research institutions in France or abroad, or from public or private research centers.
L'archive ouverte pluridisciplinaire HAL, est destinée au dépôt et à la diffusion de documents scientifiques de niveau recherche, publiés ou non, émanant des établissements d'enseignement et de recherche français ou étrangers, des laboratoires publics ou privés. 


\section{- Centronuclear myopathies}

\section{Norma Beatriz Romero and Marc Bitoun}

Norma Beatriz ROMERO, MD, PhD

- Head of the Unit of Neuromuscular Morphology of the Institute of Myology

- From the Institute of Myology, Inserm UMRS 974, CNRS UMR 7215 - UPMC-University Paris 6 UM74, GHU Pitié-Salpêtrière.

- Mailing address:

Institut de Myologie, Inserm UMR974, Groupe Hospitalier Universitaire Pitié-Salpêtrière, Batiment Risler

47, boulevard de l'Hôpital.

F-75 651 Paris Cedex 13 - France

Phone: +331421622 42; Fax: +33142162240

E-mail:nb.romero@institut-myologie.org

Marc BITOUN, PhD

- Investigator in the Inserm UMRS 974, CNRS UMR 7215, UPMC University Paris 6

- From the Institute of Myology, Inserm UMRS 974, CNRS UMR 7215 - UPMC-University Paris 6 UM74.

- Mailing address:

Institut de Myologie, Inserm UMR974, Groupe Hospitalier Universitaire Pitié-Salpêtrière, Batiment Babinski.

47, boulevard de l'Hôpital.

F-75 651 Paris Cedex 13 - France

Phone: +331421657 18; Fax: +33142165700

E-mail: m.bitoun@institut-myologie.org

- Supported in part by the Association Institute of Myology, Association Française de lutte contre les Myopathies, Inserm UMRS 974 and Grant ANR 2011 


\section{Abstract}

Centronuclear myopathies are inherited disorders characterised by a high incidence of centrally nuclei usually placed in rows in the muscle fibres. Three main forms of CNM have been identified according to the mode of inheritance and clinical presentation: 1) The X-linked recessive form, also named myotubular myopathy (XLMTM), presenting as a severe prenatal or neonatal myopathy in the large majority of cases, caused by mutations in the MTM1 gene; 2) the classical autosomal dominant and sporadic forms, associated with mild, moderate or severe phenotypes caused by mutations in the DNM2 gene; and 3) an autosomal recessive form presenting with severe and moderate phenotypes caused by mutations in BIN1 gene. The three CNM genes are involved in membrane remodelling and membrane trafficking and impairment of these processes could be a common CNM pathomechanism. In addition, recent data gained in human biopsies or animal models highlighted a possible dysfunction of the T-tubule system in CNM. 


\section{Introduction}

Congenital myopathies with central nuclei or centronuclear myopathies (CNM) are genetically inherited disorders classically identified by the presence of an abnormally high number of muscle fibres with nuclei placed in rows in the central part of the fibre. The clinical presentations of patients are extremely heterogeneous ranging from severe hypotonia in newborns to a relatively late onset of muscle weakness with extraocular muscles involvement in adolescent and young adults.

The early classification of centronuclear myopathies was mainly based on the age of onset and the severity of clinical symptoms. The first group identified during the sixties was the early-adult onset with moderate and mild forms, and then the group composed of severe cases detected in the neonatal period, on male newborns, with a recessive $X$-linked inheritance [see review in ${ }^{1}$ ]. This recessive X-linked myotubular myopathy (XLMTM) is caused by mutations in the MTM1 gene ${ }^{2}$ encoding the myotubularin 1 (MTM1). On the other hand, numerous sporadic patients and some families with pedigrees showing an obvious autosomal inheritance have been recognized ${ }^{3}$. Thereafter, two causative genes of autosomal CNM were identified, i.e. the DNM2 gene ${ }^{4}$ encoding the dynamin 2 (DNM2) in the autosomal dominant CNM (AD-CNM) and the BIN1 gene ${ }^{5}$ coding for the amphiphysin 2 (BIN1) in the autosomal recessive CNM (AR-CNM). However, a lot of sporadic or familial CNM cases are not yet genetically resolved, implying the existence of additional causative genes.

Noteworthy, a heterozygous RYR1-mutation has been found in a single patient with the initial diagnosis of CNM and core-like lesions in the muscle biopsy ${ }^{6}$, and recessive $R Y R 1$-mutations has been reported in some patients with congenital myopathy harbouring a peculiar morphological pattern with prominent nuclear internalisation and large areas of myofibrillar disorganisation (personal communication in the 164th International ENMC Workshop/January 2009) ${ }^{7}$. Afterwards, it has been established that patients in whom an initial diagnosis of centronuclear myopathy was established because the high number of internalised nuclei observed in the muscle biopsy performed in early age, indeed, correspond to a form of AR-RYR1-related congenital myopathy ${ }^{8,9}$.

Here, we report an overview of the clinical and morphological features of the MTM1- DNM2and BIN1-related CNM and discuss the pathophysiological hypotheses emerging from recent studies using tissue from patients and animal models for these three main CNM genes. 


\section{Clinical and morphological features in CNM}

\subsection{Recessive X-linked Myotubular myopathy}

The term myotubular myopathy was initially used by Spiro et al, in $1966^{10}$; and had defined a distinct congenital myopathy because the morphologic alterations of the muscle fibre closely resembling the myotubular stage of development. Even though at the beginning this term was overall used to the group of congenital myopathies with central nuclei, the term myotubular myopathy was secondarily restricted to the X-linked recessive form (XLMTM), affecting mainly male patients [see review in ${ }^{1}$. The affected newborn boys present mostly with severe hypotonia, wasting muscle and generalized weakness at birth, almost always associated with respiratory insufficiency requiring immediate ventilator support and swallowing difficulties needing a feeding tube to prevent early death due to aspiration (Figure 1). Antenatal signs as reduced foetal movements, polyhydramnios and thin ribs are typically found. Ocular muscle involvement, moderate ptosis and external ophthalmoplegia, are often observed after the neonatal period. The affected infants are usually macrosomic associating asymmetric muscle bulk and may have diverse malformations comprising pyloric stenosis, inguinal hernia and undescended testes. The neonatal form of XLMTM carries a poor prognosis, the large majority of patients die within the first months of life, but a relatively small proportion of boys may be less affected in the neonatal period and survive into childhood and even adulthood. Interestingly, some affected boys acquire the ability to walk with a quite autonomous life ${ }^{11-13}$. However, many patients surviving through the infancy usually remain severely impaired and require intensive physiotherapy and adapted rehabilitation (permanent ventilation, brace with head support, even feeding tube).

The morphologic analysis of muscle biopsies shows a characteristic high number of small muscle fibres with centralised nuclei and a predominance of type 1 fibres ${ }^{14}$. Frequently there are also some large type 1 fibres which correspond to remaining Wohlfart B Fibers. On transverse muscle sections crossing the fibre between two adjacent nuclei, the central area of the fibres displays reduced myofibrillar ATPase reaction and increased oxidative enzymes activity and glycogen staining. Noticeable, in sections reacted for oxidative enzymes activity, numerous muscle fibres show a pale halo at the periphery of the fibre, and the few large type 1 Wohlfart B Fibers fibres show a strong oxidative staining (Figure 1). On longitudinal sections, chains of nuclei are observed in the central part 
of the fibre. The ultrastructural analyses show that for the most part the myofibrils are restrained in the peripheral zones of the fibres. By contrast, the central areas of myofibres are mainly occupied by aggregates of mitochondria and glycogen particles whereas the myofilaments are lacking (Figure 1). By immunohistochemistry we have recognized a positive labelling mainly in the central areas of the muscle fibres with antibodies for DHPR $\alpha 1$ s (the dihydropyridine receptor- $\alpha 1$ subunit) a $\mathrm{Ca}^{2+}$ channel of the T-tubule, and RYR1 (the ryanodine receptor type 1) a $\mathrm{Ca}^{2+}$ channel of the sarcoplasmic reticulum. The wholly cytoplasm was positive for desmin with increased staining in the central areas of the fibres; and the caveolin3 the immunolabelling was normally observed in the sarcolemma (Figure 5).

Recently, the presence of necklace fibres in muscular biopsies was observed in sporadic lateonset MTM1-related centronuclear myopathy ${ }^{15}$. The clinical symptoms are mild during childhood, and worsened after the first or second decades of the live. Necklace fibres are characterized by a basophilic ring deposit following the contour of the cell, in which myonuclei are aligned (Figure 2). Under electron microscopy, the necklaces show myofibrils with oblique orientation and they have smaller diameter than the myofibrils placed in the normally structured surrounding areas ${ }^{14,15}$.

\subsection{Autosomal dominant DNM2-related centronuclear myopathy}

Several clinical phenotypes of autosomal dominant DNM2-related CNM have been reported, they range from mild forms in adult patients to severe forms in infants. The classical phenotype of centronuclear myopathy corresponds clinically to mild or late-childhood and adult onset forms ${ }^{4}$, but then, an intermediate form in adults with early onset of the disease has been also reported ${ }^{16}$. In paediatric population initially we described sporadic cases corresponding with the severe and earlyonset clinical form ${ }^{17}$; afterwards we demonstrated a marked variability in clinical presentation severity of CNM associated with mutations in $D N M 2^{18}$. In general, adolescent and young adult patients with moderate phenotype had normal pregnancy and delivery but motor milestones are typically delayed, especially walking and then climbing stairs and running. Moderate skeletal muscle weakness associated with ptosis and ophthalmoplegia are constant. On the other hand, paediatric patients usually have generalised weakness, hypotonia, moderate degree of facial weakness with open mouth, ptosis and ophthalmoplegia (Figure 3). Achilles tendon contractures, scoliosis, reduced jaw opening, mild pes cavus and pronounced atrophy of calves and thenar eminences often complete the clinical phenotype ${ }^{17,18}$. 
The analysis of muscle biopsies of DNM2-related CNM shows a characteristic triad of morphological features: a) a radial arrangement of sarcoplasmic strands with oxidative enzyme reactions conferring a spokelike appearance, b) significant nuclear centralisation and internalisation (Figure 3), c) type 1 muscle fibre predominance and hypotrophy. Interesting, this complete histopathological triad of features has been exclusively found in DNM2-associated CNM. However, in young DNM2-related children the characteristic triad of features could be absent or quantitatively less important ${ }^{16}$. Increase in fibro-adipose endomysial tissue may be present in DNM2-related CNM; this makes sometimes the initial pathological diagnosis quite difficult. At electron microscopy, the central nuclei appear without morphological abnormality and the radial distribution of the intermyofibrillar sarcoplasmic strand is easily recognized (Figure 3). Typically, the diameter of the myofibrils became progressively smaller from the periphery to the central zone of the fibre, giving rise to radiating appearance ${ }^{1,14}$; in addition, the central internuclear spaces are occupied by mitochondria, rough endoplasmic reticulum, Golgi complex and glycogen particles. By immunohistochemistry we have documented a diffuse positive labelling in the wholly cytoplasm of the muscle fibres with antibodies for DHPR $\alpha 1$ s, RYR1 and desmin. In a few fibres, the central areas have a desmin immunostaining moderately increased; and for caveolin3, the immunolabelling was normally observed in the sarcolemma (Figure 5).

We reported the clinical and muscle imaging findings of ten patients with late-onset CNM harbouring DNM2 mutations ${ }^{19}$. In all ten patients, muscle computer tomography assessment showed a characteristic temporal course with early and predominant distal muscle involvement and later affection of the posterior thigh compartment and gluteus minimus muscles. The recognition of this specific imaging pattern - distinct to the reported patterns in other congenital myopathies - may enable a better selection for direct genetic testing.

\subsection{Autosomal recessive BIN1-related centronuclear myopathy}

Although a few cases were indentified with autosomal recessive BIN1-related centronuclear myopathy so far, these patients present with a large clinical variability from the severe to moderate phenotypes ${ }^{5,20-22}$. Pregnancy and birth can occur without major events, however delayed motor milestones, difficulties to run, walking and climb stairs since childhood are common antecedents. 
Muscular atrophy, diffuse weakness, facial diplegia, ptosis and varying degrees of ophtalmoplegia are usually present.

The muscle biopsies analysis from BIN1-related CNM shows numerous rounded small type 1 fibres, with central nuclei in the large majority of them ${ }^{14}$. Interesting, clusters of centrally placed nuclei and rows of central nuclei have been observed in some muscle fibres ${ }^{14}$ (Figure 4). The electron microscopy findings show central placed nuclei and an internuclear spaces occupied by an amorphous material containing mitochondria, sarcotubular structures and glycogen particles (Figure 4). By immunohistochemistry, we demonstrated a strictly positive labelling in the central areas of the muscle fibres with antibodies for DHPR $\alpha 1$ s, RYR1 and desmin, giving a small colourless area with dark dotted underlining, mainly around the central nuclei. The cytoplasm is also labelled with these three antibodies. Noticeable, the caveolin3 immunolabelling was observed normally in the sarcolemma but strangely associated with increased staining in the central areas of the fibres (Figure 5).

\section{CNM genes and pathophysiological hypotheses}

The recessive XLMTM with severe neonatal phenotype and the late-onset form with necklace fibres is caused by mutations in the MTM1 gene, located on Xq28 chromosome and composed of 15 exons coding for a 603 amino-acids protein ${ }^{2}$. MTM1 mutations lead to the decrease or absence of the gene product in most of the cases. Although XLMTM affects above all newborn and children males; rare female infants have been reported, usually associated with large DNA rearrangements. In addition, mainly symptomatic female carriers have been related due to a probable skewed Xinactivation. The MTM1 gene encodes the myotubularin 1 (MTM1) which is a 3-phosphoinositides phosphatase for the phosphatidylinositol $(3,5)$ bisphosphate $(\mathrm{PI}(3,5) \mathrm{P} 2)$ and the phosphatidylinositol (3) monophosphate (PI3P) leading to the production of PI5P and PI, respectively. The PI3P and $\mathrm{PI} 3,5 \mathrm{P} 2$ are second messengers located at the membrane surface of the endosomal system and have been involved in membrane remodelling and trafficking ${ }^{23}$.

The autosomal dominant CNM is due to heterozygous mutations in the DNM2 gene at the $19 p 13$ locus composed of 22 exons. Mutations in this gene have been also identified in rare intermediate and axonal forms of the Charcot-Marie-Tooth (CMT) peripheral neuropathy ${ }^{24}$. DNM2 is a large GTPase mainly involved in membrane trafficking through its function in the formation and release of nascent vesicles from biological membranes. DNM2 participates in clathrin-dependent and clathrin- 
independent endocytosis and intracellular membrane trafficking (from endosomes and Golgi apparatus). In addition, DNM2 tightly interacts with, and is involved in the regulation of actin and microtubule networks 25 .

The autosomal recessive CNM is due to mutations in the BIN1 gene ${ }^{5}$ located to the locus $2 q 14$ and composed of 20 exons. Like MTM1 and DNM2, BIN1 is ubiquitously expressed but specific BIN1 muscular isoform exists. BIN1 belongs to the endocytosis machinery in which the protein is involved in membrane curvature and tubulation via its BAR (Bin/Amphiphysin/Rsv167) domain and recruitment of endocytosis-associated proteins via its SH3 (SRC homology-3) domain such as $\mathrm{DNM}^{26,27}$.

It is interesting to note that despite the differences in the clinical presentation and their evolution, and the pathological features in muscle biopsy, all known gene products causing centronuclear myopathy are involved in membrane remodelling, endocytosis and intracellular membrane trafficking. Indeed, impairment of endocytosis and membrane trafficking was reported in cultured cells expressing MTM1 and DNM2 mutants $24,28-31$. The question which remains to be explored is how trafficking impairment due to mutation in ubiquitous proteins can induce a tissue-specific phenotype. On the other hand, it was reported that the muscle specific isoform of amphiphysin 2 is concentrated at T-tubules in mouse and drosophila and was involved in the organization of this plasma membrane invagination acting in excitation-contraction coupling ${ }^{32,33}$. Interestingly, MTM1 was also located to the T-tubules in mouse ${ }^{34}$ and zebrafish ${ }^{35}$ and knock-down of myotubularin in these species leads to disorganisation of the T-tubule system and defect in excitation-contraction coupling ${ }^{35,36}$. More recently, abnormalities in T-tubule morphology was also reported in mouse muscle overexpressing a CNM-related DNM2 mutant ${ }^{37}$. In addition, defects in T-tubule and triad structures have been reported in muscle biopsies from MTM1-, BIN1- and DNM2-CNM patients ${ }^{5,35-38}$. Altogether, these data argue for a common pathomechanism in CNMs in which T-tubule dysfunction leads to an excitation-contraction coupling impairment. Further studies will be necessary to determine if the Ttubule defects are associated with an impairment of intracellular trafficking processes in which MTM1, DNM2 and BIN1 have been involved or if these defects could be related to a muscle-specific function of the three CNM proteins which remains to be determined.

A novel pathophysiological mechanism was recently reported in the MTM1-CNM ${ }^{39}$. Hnia et al. showed that MTM1 is a desmin-binding protein and that MTM1 mutants alter the desmin network 
architecture and mitochondrial homeostasis. In agreement with this hypothesis we show here that desmin network is disorganized in the three forms of CNM (Figure 5). Indeed, the immunocytochemical staining for desmin in muscle cross-sections from CNM patients has revealed, besides a diffuse cytoplasm localisation, a particular distribution of the protein which appears increased in the central areas of the fibres, mainly in BIN1- and relatively less in MTM1-related CNM. The presence of high immunolabelling in the central areas of muscle is also observed for DHPR and RYR1.

\section{RYR1-linked congenital myopathy with multiple internal nuclei and myofibrillar disorganisation}

Whereas the histopathological alterations in skeletal muscle increase with age, muscle biopsies performed in young patients, sometimes could not show all structural abnormalities that characterize the morphological phenotypes of congenital myopathies. In this context, a group of patient sharing high number of internalised nuclei and large and poorly defined areas of myofibrillar disorganisation in the muscle biopsy performed in early age was originally classified in the group of CNM not linked to the DNM2 gene ${ }^{14}$. In these patients, clinical symptoms usually onset during the neonatal period with a predominant axial and proximal weakness of diverse severity, associated with facial weakness, bilateral ptosis and ophthalmoparesis, occasional restrictive respiratory syndrome and contractures. The muscle biopsies analysis revealed unusual pattern characterised by significant myonuclei internalisation and muscle fibres showed large areas devoid of ATPase activity and irregular oxidative enzymatic reaction; some fibres presenting with a fuchsinophilic granular precipitate as purple dusty fibres. At electron microscopy, the large zones of myofibrillar disorganisation frequently occupied the whole myofibre cross-section and extended to a few sarcomeres in length, Zdisk streaming and accumulated Z-disk proteins and depleted of mitochondria are frequently observed.

In this group of patients, a heterozygous RYR1-mutation has been found in a single patient with the initial diagnosis of CNM and core-like lesions in the muscle biopsy ${ }^{6}$, and recessive RYR1mutations has been recently reported in the other patients ${ }^{8-9}$ suggesting that this phenotype is a form of AR-RYR1-related congenital myopathy. 


\section{References}

1. Fardeau M, Tome F. Congenital myopathies. In: Engel AG, Franzini-Armstrong C, editors. Myology. New York: McGraw Hill; 1994. p. 1500-25.

2. Laporte J, Hu LJ, Kretz C, Mandel JL, Kioschis P, Coy JF, et al. A gene mutated in X-linked myotubular myopathy defines a new putative tyrosine phosphatase family conserved in yeast. Nat Genet 1996;13:175-82.

3. Jeannet PY, Bassez G, Eymard B, Laforet P, Urtizberea JA, Rouche A, et al. Clinical and histologic findings in autosomal centronuclear myopathy. Neurology 2004;62:1484-90.

4. Bitoun $M$, Maugenre $S$, Jeannet $P Y$, Lacène $E$, Ferrer $X$, Laforêt $P$, et al. Mutations in dynamin 2 cause dominant Centronuclear Myopathy. Nature Genet 2005;37:1207-09.

5. Nicot AS, Toussaint A, Tosch V, Kretz C, Wallgren-Pettersson C, Iwarsson E, et al. Mutations in amphiphysin 2 (BIN1) disrupt interaction with dynamin 2 and cause autosomal recessive centronuclear myopathy. Nat Genet 2007;39:1134-39.

6. Jungbluth $\mathrm{H}$, Zhou H, Sewry CA, Robb S, Treves S, Bitoun M, et al. Centronuclear myopathy due to a de novo dominant mutation in the skeletal muscle ryanodine receptor (RYR1) gene. Neuromuscul Disord 2007;17:338-45.

7. Jungbluth $\mathrm{H}$, Wallgren-Pettersson $\mathrm{C}$, Laporte JF. On behalf of the Centronuclear (myotubular) myopathy consortium. In: 164th ENMC international workshop: 6th workshop on centronuclear (myotubular) myopathies, 16-18th January 2009, Naarden, The Netherlands. Neuromuscul Disord. 2009; 19: 721-9.

8. Wilmshurst JM, Lillis S, Zhou H, Pillay K, Henderson H, Kress W, et al. RYR1 mutations are a common cause of congenital myopathies with central nuclei. Ann Neurol 2010;68:717-26.

9. Bevilacqua JA, Monnier N, Bitoun M, Eymard B, Ferreiro A, Monges S, et al. Recessive RYR1 mutations cause unusual congenital myopathy with prominent nuclear internalisation and large areas of myofibrillar disorganisation. Neuropathol Appl Neurobiol. 2011;37:271-84.

10. Spiro AJ, Shy GM, Gonatas NK. Myotubular myopathy. Persistence of fetal muscle in an adolescent boy. Arch Neurol 1966;14:1-14.

11. Biancalana V, Caron O, Gallati S, Baas F, Kress W, Novelli G, et al. Characterisation of mutations in 77 patients with X-linked myotubular myopathy, including a family with a very mild phenotype. Hum Genet 2003;112:135-42. 
12. Chanzy S, Routon MC, Moretti S, de Gennes C, Mselati JC. [Unusual good prognosis for Xlinked myotubular myopathy]. Arch Pediatr 2003;10:707-09.

13. Tosch V, Vasli N, Kretz C, Nicot AS, Gasnier C, Dondaine N, et al. Novel molecular diagnostic approaches for X-linked centronuclear (myotubular) myopathy reveal intronic mutations. Neuromuscul Disord 2010;20:375-81.

14. Romero NB. Centronuclear myopathies: a widening concept. Neuromuscul Disord 2010;20:223-28.

15. Bevilacqua JA, Bitoun M, Biancalana V, Oldfors A, Stoltenburg G, Claeys KG, et al.

"Necklace" fibers, a new histological marker of late-onset MTM1-related centronuclear myopathy. Acta Neuropathol 2009;117:283-91.

16. Bitoun M, Bevilacqua JA, Eymard B, Prudhon B, Fardeau M, Guicheney P, et al. A new centronuclear myopathy phenotype due to a novel dynamin 2 mutation. Neurology 2009;72:93-95.

17. Bitoun M, Bevilacqua JA, Prudhon B, Maugenre S, Taratuto AL, Monges S, et al. Dynamin 2 mutations cause sporadic centronuclear myopathy with neonatal onset. Ann Neurol 2007;62:666-70.

18. Susman RD, Quijano-Roy S, Yang N, Webster R, Clarke NF, Dowling J, et al. Expanding the clinical, pathological and MRI phenotype of DNM2-related centronuclear myopathy. Neuromuscul Disord 2010;20:229-37.

19. Fischer D, Herasse M, Bitoun M, Barragán-Campos HM, Chiras J, Laforêt P, et al. Characterization of the muscle involvement in dynamin 2- related centronuclear myopathy. Brain 2006;129:1463-69.

20. Claeys KG, Maisonobe T, Bohm J, Laporte J, Hezode M, Romero NB, et al. Phenotype of a patient with recessive centronuclear myopathy and a novel bin1 mutation. Neurology 2010;74:519-21. 21. Mejaddam AY, Nennesmo I, Sejersen T. Severe phenotype of a patient with autosomal recessive centronuclear myopathy due to a BIN1 mutation. Acta Myol 2009;28:91-93.

22. Bohm J, Yis U, Ortac R, Cakmakci H, Kurul SH, Dirik E, et al. Case report of intrafamilial variability in autosomal recessive centronuclear myopathy associated to a novel BIN1 stop mutation. Orphanet J Rare Dis 2010;5:35.

23. Nicot AS, Laporte J. Endosomal Phosphoinositides and Human Diseases. Traffic 2008;9:1240-9. 
24. Zuchner S, Noureddine M, Kennerson M, Verhoeven K, Claeys K, De Jonghe P, et al. Mutations in the pleckstrin homology domain of dynamin 2 cause dominant intermediate CharcotMarie-Tooth disease. Nat Genet 2005;37:289-94.

25. Durieux A, Prudhon B, Guicheney P, Bitoun M. Dynamin 2 and Human diseases. J Mol Med 2010;88:339-50.

26. Dong J, Misselwitz R, Welfle H, Westermann P. Expression and purification of dynamin II domains and initial studies on structure and function. Protein Expr Purif 2000;20:314-23.

27. Kojima C, Hashimoto A, Yabuta I, Hirose M, Hashimoto S, Kanaho Y, et al. Regulation of Bin1 SH3 domain binding by phosphoinositides. EMBO J 2004;23:4413-22.

28. Chaussade C, Pirola L, Bonnafous S, Blondeau F, Brenz-Verca S, Tronchere H, et al. Expression of myotubularin by an adenoviral vector demonstrates its function as a phosphatidylinositol 3-phosphate [Ptdlns(3)P] phosphatase in muscle cell lines: involvement of Ptdlns(3)P in insulinstimulated glucose transport. Mol Endocrinol 2003;17:2448-60.

29. Bitoun M, Durieux AC, Prudhon B, Bevilacqua JA, Herledan A, Sakanyan V, et al. Dynamin 2 mutations associated with human diseases impair clathrin-mediated receptor endocytosis. Hum Mutat 2009;30:1419-27.

30. Tanabe K, Takei K. Dynamic instability of microtubules requires dynamin 2 and is impaired in a Charcot-Marie-Tooth mutant. J Cell Biol 2009;185:939-48.

31. Durieux AC, Vignaud A, Prudhon B, Thao Viou M, Beuvin M, Vassilopoulos S, et al. A centronuclear myopathy-dynamin 2 mutation impairs skeletal muscle structure and function in mice. Hum Mol Genet 2010;19:4820-36.

32. Lee E, Marcucci M, Daniell L, Pypaert M, Weisz OA, Ochoa GC, et al. Amphiphysin 2 (Bin1) and T-tubule biogenesis in muscle. Science 2002;297:1193-96.

33. Razzaq A, Robinson IM, McMahon HT, Skepper JN, Su Y, Zelhof AC, et al. Amphiphysin is necessary for organization of the excitation-contraction coupling machinery of muscles, but not for synaptic vesicle endocytosis in Drosophila. Genes Dev 2001;15:2967-79.

34. Buj-Bello A, Fougerousse F, Schwab Y, Messaddeq N, Spehner D, Pierson CR, et al. AAVmediated intramuscular delivery of myotubularin corrects the myotubular myopathy phenotype in targeted murine muscle and suggests a function in plasma membrane homeostasis. Hum Mol Genet 2008;17:2132-43. 
35. Dowling JJ, Vreede AP, Low SE, Gibbs EM, Kuwada JY, Bonnemann CG, et al. Loss of myotubularin function results in T-tubule disorganization in zebrafish and human myotubular myopathy. PLoS Genet 2009;5:e1000372.

36. Al-Qusairi L, Weiss N, Toussaint A, Berbey C, Messaddeq N, Kretz C, et al. T-tubule disorganization and defective excitation-contraction coupling in muscle fibers lacking myotubularin lipid phosphatase. Proc Natl Acad Sci 2009,106:18763-68.

37. Cowling BS, Toussaint A, Amoasii L, Koebel P, Ferry A, Davignon L, et al. Increased expression of wild-type or a centronuclear myopathy mutant of dynamin 2 in skeletal muscle of adult mice leads to structural defects and muscle weakness. Am J Pathol 2011;178:2224-35.

38. Toussaint A, Cowling BS, Hnia K, Mohr M, Oldfors A, Schwab Y, et al. Defects in amphiphysin 2 (BIN1) and triads in several forms of centronuclear myopathies. Acta Neuropathol. 2011;121:253-66. 39. Hnia K, Tronchere H, Tomczak KK, Amoasii L, Schultz P, Beggs AH, et al. Myotubularin controls desmin intermediate filament architecture and mitochondrial dynamics in human and mouse skeletal muscle. J Clin Invest 2011;121:70-85

\section{Figures}

\section{Figure 1}

Newborn boy with severe X-linked myotubular myopathy: Note severe hypotonia, ptosis and respiratory distress requiring assisted ventilation and gastric feeding (A). Cryostat transverse muscle sections $(B, C)$ show many fibres with central nuclei resembling myotubes $(B, H \& E)$; and the oxidative staining reveals the fibres with a dark central region which are regularly surrounded by a paler peripheral halo ( $\mathrm{C}, \mathrm{NADH}-\mathrm{TR})$. Under the electron microscope, the transverse sections show the nuclei in the centre of the fibre often bordered by mitochondria, glycogen and some tubular structures (D). In sections crossing the muscle fibre between two adjacent nuclei, the central area of the fibres displays strikingly a reduction of myofilaments $(E)$.

\section{Figure 2}

Seven-year-old girl affected by DNM2-related CNM: Note Mild facial weakness, bilateral ptosis and open mouth (A). Cryostat transverse muscle section shows a high percentage of small rounded 
fibres with centralised nuclei $(B, H \& E)$; and few fibres with typical aspect of radiating sarcoplasmic strands with NADH-TR reaction (D). Ultrasturural photograph showing a nucleus in the centre of the fibre and the radial distribution of sarcoplasmic strands at high magnification (C).

\section{Figure 3}

Late-onset MTM1-related CNM: Transverse cryostat muscle sections showing typical necklace fibres with a ring deposit following the contour of the cell in the subsarcolemmal area in which myonucleus are aligned (A, H\&E; B, GT). Ultrastructural photographs of transverse section of a necklace fibre showing the nucleus aligned with the necklace which corresponds with myofibrils of smaller diameter and oblique orientation, increased number of mitochondria, tubules and glycogen (C).

\section{Figure 4}

BIN1-related CNM: Note the cluster of centrally placed nuclei in a muscle fibre $(A, H \& E)$ and rows of clusters of central nuclei in longitudinal section $(\mathrm{B}, \mathrm{H} \& \mathrm{E})$. Under the electron microscope, the longitudinal section shows nuclei in the central area of the fibre and the amorphous material containing mitochondria, tubules and glycogen.

\section{Figure 5}

Muscle biopsies sections of patients with severe $X$-linked myotubular myopathy $(A, B, C, D)$, and DNM2- $(\mathrm{E}, \mathrm{F}, \mathrm{G}, \mathrm{H})$ and BIN1-related CNM patients $(\mathrm{I}, \mathrm{J}, \mathrm{K}, \mathrm{L})$ showing Immunohistochemical findings of $\operatorname{DHPR}(A, E, I)$, RYR1 (B,F,J), desmin $(C, G, K)$ and caveolin3 (D,H,L).

Muscle sections in A, B and C (MTM1-) demonstrate muscle fibres with positive expression of either of DHPR, RYR1 and desmin with a labelling increased in the central areas of the fibres. Muscle sections in $\mathrm{E}, \mathrm{F}$ and $\mathrm{G}$ (DNM2-) reveal in general a relatively homogeneous and diffuse labelling of the cytoplasm. However, muscle sections in I, J and K (BIN1-) show a labelling strictly increased in the central areas of the fibres with an intense coloration in the cytoplasm. Noticeable, the immunolabelling for caveolin3 was observed normally in the sarcolemma in MTM1- (D) and DNM2- $(\mathrm{H})$ related CNM, but it was peculiarly associated with increased staining in the central areas of the fibres in BIN1related CNM (L). 


\section{Acknowledgements}

We sincerely thank Professor Michel Fardeau for advice, and the patients and the parents of the

patients. We wish to thank the laboratory engineers and technicians for the excellent technical work: L. Manéré, M.T. Viou, E. Lacène, M. Beuvin, G. Brochier, D. Chauveau, B. Prudhon. 


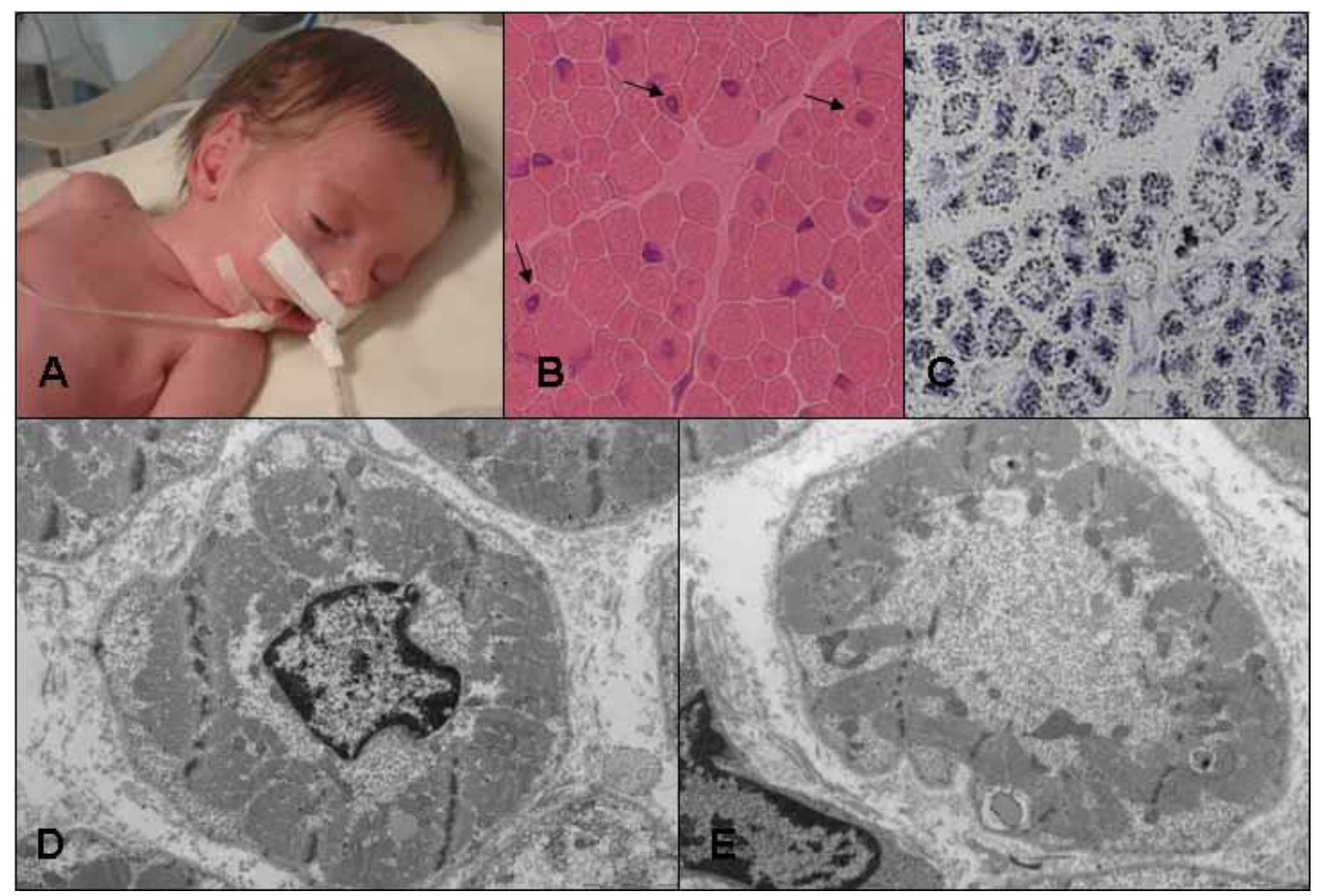

Figure 1 


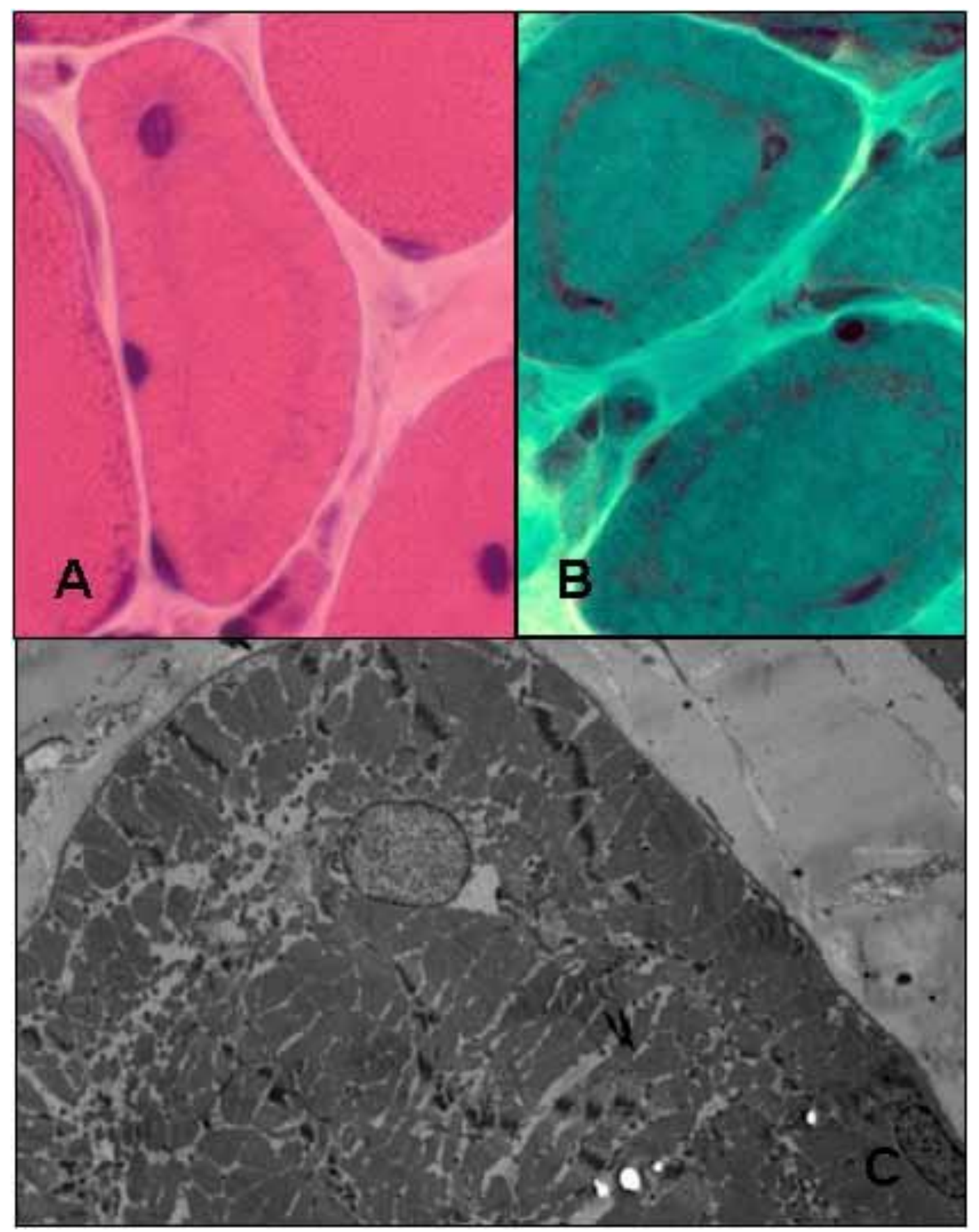

Figure 2 


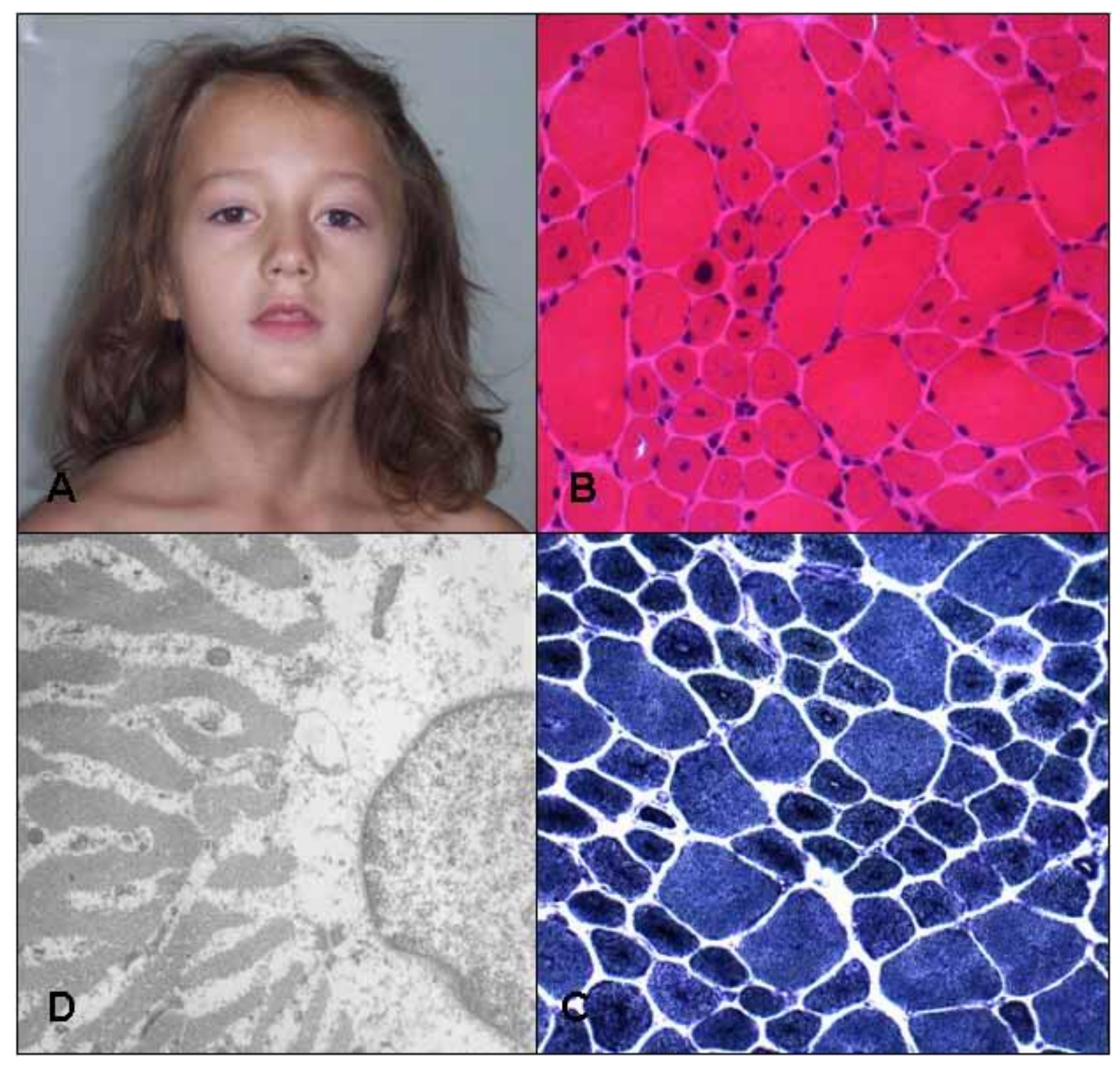

Figure 3 


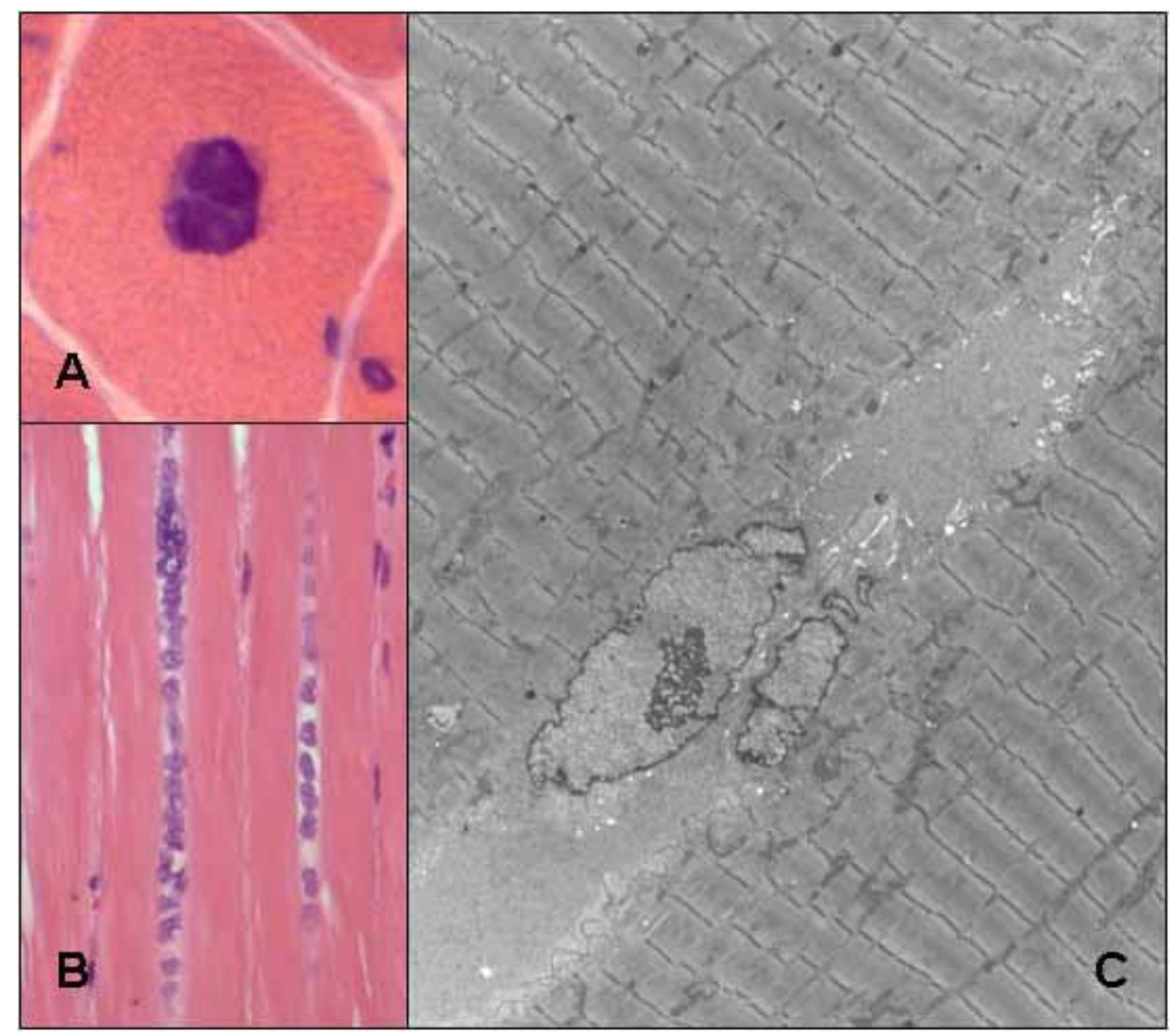

Figure 4 

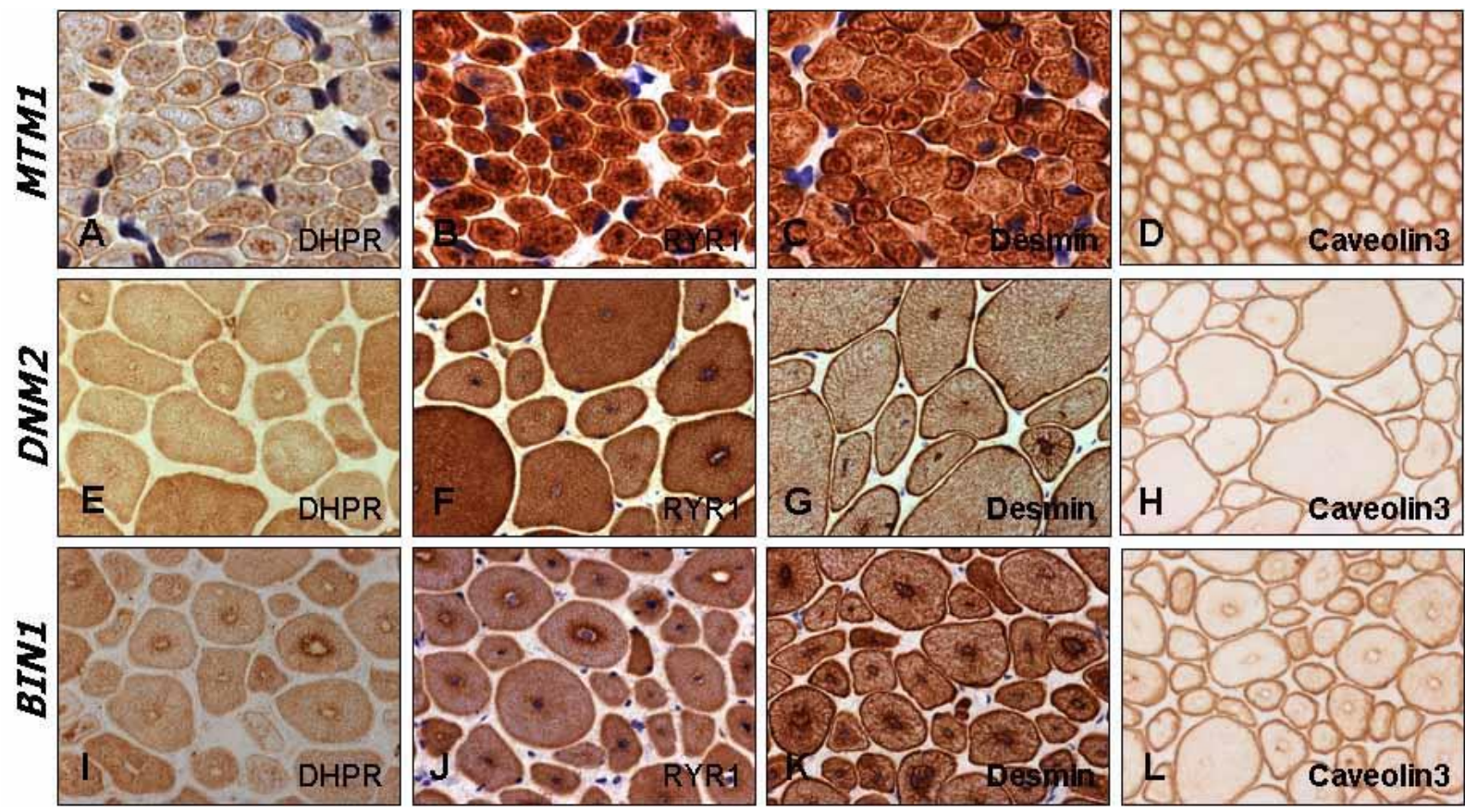

Figure 6 